\title{
DYSFUNCTIONS OF RUSSIAN MARKET OF MERGERS AND ACQUISITIONS: CAUSES, CONSEQUENCES, METHODS OF OVERCOMING
}

\author{
Anastasia G. Alekseenko \\ Kuban State Technological University, Krasnodar, Russian Federation
}

\begin{abstract}
The article deals with studying the institutional dysfunction of the Russian market of mergers and acquisitions. It proves that problems of functioning and quality of formal regulating institutions hinder its effective development. The contradiction of interests between the state as a subject of regulation and the state as a participant of the market resulted in forming institutional microdysfunctions connected with "double standards" of law enforcement for different types of owners, striving to obtain bureaucracy rent, intertwining functional actions of the state as a regulator and the state as a market participant. This contributed to the regular blocking of the trap effect in applying valuation norms in the antitrust law, causing impossibility to effectively prevent unfair deals and at the same time hinder fair and effective deals in the Russian market of mergers and acquisitions. To settle this problem it is required to use changes aimed at reducing asymmetric information between subjects of the Russian market of mergers and acquisitions and the state, and also blocking informal institutions which are in conflict with formal regulating institutions. Improving evaluation methods of economic analysis in the antitrust practice, expanding informal control (such as making independent expert research of future substantial deals and also analyzing performed deals) will contribute to overcoming the existing dysfunctions of the Russian market of mergers and acquisitions.
\end{abstract}

Key words: mergers, acquisitions, institutional microdysfunctions, institutional trap, effectiveness.

Citation. Alekseenko A.G. Dysfunctions of Russian Market of Mergers and Acquisitions: Causes, Consequences, Methods of Overcoming. Journal of Volgograd State University. Economics, 2019, vol. 21, no. 3, pp. 29-35. (in Russian). DOI: https://doi.org/10.15688/ek.jvolsu.2019.3.3

УДК 330.341

Дата поступления статьи: 20.06.2019

ББК 65.01

Дата принятия статьи: 10.07.2019

\section{ДИСФУНКЦИИ РОССИЙСКОГО РЫНКА СЛИЯНИЙ И ПОГЛОЩЕНИЙ: ПРИЧИНЫ, ПОСЛЕДСТВИЯ, СПОСОБЫ ПРЕОДОЛЕНИЯ}

\author{
Анастасия Германовна Алексеенко \\ Кубанский государственный технологический университет, г. Краснодар, Российская Федерация
}

\begin{abstract}
Аннотация. Статья посвящена исследованию институциональных дисфункций российского рынка слияний и поглощений. Установлено, что проблемы функционирования и качества формальных регулирующих институтов обусловили торможение его эффективного развития. Асимметрия интересов государства как субъекта регулирования и как участника указанного рынка привела к формированию институциональных микродисфункций, ح связанных с «двойными стандартами» правоприменения для разных классов собственников, поиском бюрократи$\overline{\mathcal{尺}}$ ческой ренты, смешением функциональных воздействий государства-регулятора и государства-рыночногосубъекـ та. Это способствовало закреплению ловушки применения оценочных норм антимонопольного законодательства, реализующейся в невозможности эффективного пресечения недобросовестных сделок и одновременно в торможении обоснованных и эффективных сделок на российском рынке слияний и поглощений. Решение данных проблем требует преобразований, направленных на снижение асимметричности информации между субъектами российского рынка слияний и поглощений и государством, а также блокировку неформальных институтов, конфликтующих с формальными регулирующими институтами. Совершенствование оценочного аппарата эко(?) номического анализа в антимонопольной практике, расширение неформального контроля (проведение независи-
\end{abstract}


мых экспертных исследований предполагаемых значимых сделок, а также анализа свершившихся сделок) будут способствовать преодолению существующих дисфункций российского рынка слияний и поглощений.

Ключевые слова: слияния, поглощения, институциональные микродисфункции, институциональная ловушка, эффективность.

Цитирование. Алексеенко А. Г. Дисфункции российского рынка слияний и поглощений: причины, последствия, способы преодоления // Вестник Волгоградского государственного университета. Экономика. -2019. - Т. 21, № 3. - С. 29-35. - DOI: https://doi.org/10.15688/ek.jvolsu.2019.3.3

\section{Введение}

Российский рынок слияний и поглощений начал активно развиваться сравнительно недавно, однако в своем становлении пережил уже несколько этапов. Сделки слияния и поглощения являются одним из наиболее распространенных методов приобретения прав корпоративного контроля в нашей стране. Несмотря на то что число сделок на рынке слияний и поглощений за последние несколько лет монотонно сокращалось, объем стоимости и средняя цена сделки показывают тенденцию к росту. По мнению ряда экспертов, компании малого и среднего бизнеса в настоящее время перестали быть активными участниками указанного рынка и определяющими для него становятся действия крупного бизнеса, демонстрирующего экспансионистские интересы. Необходимо принимать во внимание, что в ходе слияний и поглощений потенциально создаются условия для усиления экономической власти отдельных субъектов, чьи частные интересы могут противоречить экономически эффективному перераспределению прав корпоративного контроля и, как следствие, препятствовать выполнению рынком слияний и поглощений своих функций. Следует отметить, что эффективность выполнения этих функций во многом зависит от действий государства как регулятора и рыночного субъекта [Сухарев, 2018, c. 277]. Масштаб дисфункций рынка и провоцируемых ими негативных эффектов определяется институциональной средой экономической системы. В связи с этим особую актуальность представляет исследование причин формирования дисфункций российского рынка слияний и поглощений, порождаемых ими эффектов и способов их преодоления.

\section{Результаты и обсуждение}

Зарождение основ формальных норм, регулирующих российский рынок слияний и по- глощений, пришлось на 1990-е гг. в условиях еще не сформировавшихся институтов рынка. Процесс создания и закрепления новых норм, определяющих поведение экономических субъектов, шел параллельно с медленным распадом прежних институтов командно-административной системы хозяйствования, что неизбежно повлекло за собой нарушение экономической координации. При фактически не функционировавших формальных институтах организацию взаимодействия экономических субъектов определяли неформальные правила. В связи с этим начальный этап становления российского рынка слияний и поглощений характеризовался массовым захватом собственности путем недружественных сделок, реализуемых через криминальные схемы. Адекватная ответная реакция государства на данные явления была невозможна, так как создаваемые регулирующие правовые нормы были не адаптированы к существующей экономической реальности, противоречили друг другу и обладали множеством «дыр», что провоцировало поиск бюрократической ренты и рост коррупции. При этом формы организации бизнеса в 1990-е гг. были непрозрачными и не отражали фактическую структуру взаимодействий, основанную на неформальных практиках.

С 2000-х гг. институциональный фон российского рынка слияний и поглощений начинает меняться. Однако также модифицировались и продолжили свое действие институциональные механизмы, препятствовавшие в 1990-е гг. росту спроса на эффективные экономические институты. Из разрозненных неформальных практик сформировалась система коррупционных правил [Барсукова, 2016, c. 22]. Коррупция становится неформальным институтом защиты прав собственности и используется как оборонительная стратегия бизнеса. При этом одним из условий эффективного развития рынков, в том числе и рын- 
ка слияний и поглощений, является адекватная реализация защиты прав собственности и независимость судебных органов, что способствует снижению негативных рыночных эффектов.

Некоторая часть представителей крупного бизнеса стала обладать «монопольным доступом к центру принятия политических решений». В результате стал складываться «двойной стандарт правил рыночной игры» для разных классов собственников. Подобный стандарт, чаще всего выражающийся в селективном правоприменении, оказал влияние на всю российскую хозяйственную систему в целом, в том числе неблагоприятно сказался на координации рынка слияний и поглощений, так как подчинение судебной исполнительной власти частным интересам крупных собственников в целях борьбы с конкурентами препятствует эффективному перераспределению прав корпоративного контроля [Антоненко, 2013, c. 117].

Также «двойные стандарты правил игры» для субъектов российского рынка слияний и поглощений могут выражаться в неформальной поддержке государством участников сделок. В большинстве случаев она ориентирована на достижение тех целей, которых добиваются инициаторы слияния или поглощения. Российская практика показала, что непосредственно форма поддержки зависит от целого ряда обстоятельств: масштаба деятельности компании-цели и ее места в отрасли; рентабельности, ликвидности и кредитоспособности компании-цели; стадии осуществления сделки; дружественная она или нет. Вышеописанная неформальная поддержка была широко распространена в 2000-е годы. В основном к ней прибегали при осуществлении недружественных поглощений [Зельднер и др., 2015, с. 127].

Помимо оказания вышеописанной поддержки прочих участников государство также стало активно функционировать на российском рынке слияний и поглощений как хозяйствующий субъект. Рост роли государства в качестве субъекта указанного рынка подчеркивают в своих работах А.Д. Радыгин, А.Н. Лякин, Е.В. Балацкий, Н.М. Розанова и др. Исследователи видят в этом «восстановление системы власти-собственности и госкапитализма». Взаимодействие государства с компаниями-целями на российском рынке слияний и поглощений описывается моделью «хищник - жертва». Выбор и приобретение государством интересующих активов реализуется через действия государственных корпораций. При этом данные сделки осуществляют преимущественно в отраслях либо с благоприятной рыночной конъюнктурой, либо с изначально высоким удельным весом государственного присутствия (нефтегазовый сектор, финансовый сектор, связь, транспорт и т. д.).

Хотя действующее российское законодательство провозглашает равенство государственных органов и других субъектов в гражданско-правовых отношениях, государственные органы фактически обладают значительным превосходством по сравнению с остальными участниками таких отношений. Государство может инициировать такую сделку в рамках реализации существующей государственной политики, но также мотивом может быть реализация личных замыслов определенных государственных служащих, в результате чего может наблюдаться диссонанс между целями государства-регулятора в сфере пресечения неэффективных и общественно вредных сделок и государства-агента со своими эгоистическими интересами [Балацкий, 1997; Лякин, 2010, с. 50; Радыгин, 2010, с. 80; Розанова, 2015, с. 10-15].

Асимметрия интересов государства как субъекта регулирования и как участника указанного рынка привела к формированию институциональных микродисфункций, связанных с «двойными стандартами» правоприменения для разных классов собственников, поиском бюрократической ренты, смешением функциональных воздействий государства-регулятора и государства рыночного субъекта. Данные микродисфункции формальных регулирующих институтов способствовали закреплению ловушки применения оценочных норм антимонопольного законодательства, реализующейся в невозможности эффективного пресечения недобросовестных сделок и одновременно в торможении обоснованных и эффективных сделок на российском рынке слияний и поглощений (см. рисунок). 


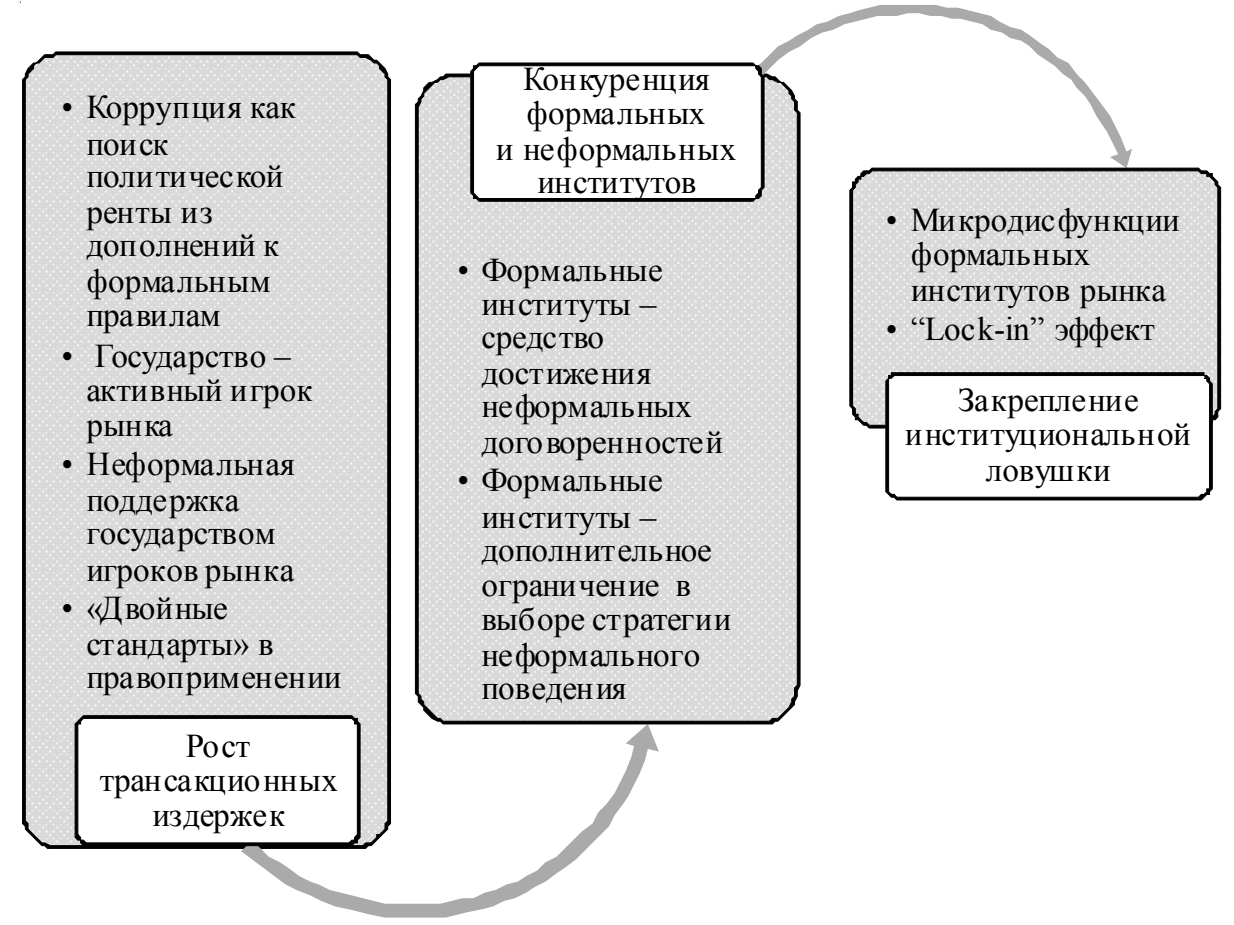

Рисунок. Механизм формирования институциональной ловушки на российском рынке слияний и поглощений

Примечание. Составлено автором.

Совершенствование институциональной среды российского рынка слияний и поглощений требует дальнейших преобразований, направленных на снижение асимметричности информации между субъектами рынка и государством, а также блокировку неформальных институтов, конфликтующих с формальными регулирующими институтами. Осуществление таких преобразований потенциально приведет к увеличению адаптивной эффективности данных институтов, а соответственно, снижению трансакционных издержек и неопределенности и, следовательно, росту эффективности российского рынка слияний и поглощений.

К примеру, важным условием для преодоления институциональной микродисфункции «двойных стандартов» правоприменения регулирующих норм, негативно влияющей на условия и результаты деятельности экономических субъектов, и обеспечения независимого судопроизводства будет последовательное соблюдение стандартов экономического анализа в практике применения оценочных норм антимонопольного законодательства. Анализ конкурентных действий субъектов на конкретных рынках и возникающих в связи с этим эффектов создает основу для единообразной правоприменительной практики в рамках регулирования процессов слияний и поглощений. Соблюдение стандартов экономического анализа в практике применения норм, регулирующих рынок слияний и поглощений, выступает важным условием исключения «двойных стандартов» правоприменения, так как снизит вероятность осуществления ошибок и повысит адаптивную эффективность существующих формальных норм путем снижения стимулов реализовывать антиконкурентные неформальные практики. Для добросовестных рыночных субъектов в результате снизятся трансакционные издержки, что приведет к повышению размера выигрышей потребителей и, следовательно, аллокативной эффективности всей хозяйственной системы в целом.

Также расширение применения стандартов экономического анализа при оценке слияний и поглощений повысит значимость деятельности общественных палат и экспертных советов по контролю поведения субъектов указанного рынка. Возможность осуществления независимого исследования перспектив предполагаемых значимых сделок слияний и погло- 
щений и анализ уже свершившихся сделок слияний и поглощений сторонними экспертами будут способствовать пресечению искажения информации и недобросовестного поведения субъектов [Шаститко, 2018, с. 120]. В дальнейшем это приведет к появлению новых эффективных форм неформального контроля на российском рынке слияний и поглощений.

Следует отразить необходимость применения стандартов экономического анализа при оценке слияний и поглощений в развиваемых ФАС России в рамках «Стратегии развития конкуренции и антимонопольного регулирования в Российской Федерации на период 20132024 гг.» институтов разъяснений и рекомендаций («guidelines»). Данные институты являются адаптацией западных институтов саморегулирования рынка слияний и поглощений, направленных на устранение асимметрии информации между регулирующими органами и субъектами рынка. В настоящий момент ФАС России ведет работу в этом направлении по разработке рекомендаций по доказыванию недопустимых соглашений и согласованных действий на товарных рынках, оценке допустимости способов ведения бизнеса субъектами, занимающими доминирующее положение на рынке, и оценке «вертикальных» соглашений.

Особого внимания заслуживают частичные поглощения, порождающие структуры общего владения собственностью. Данные сделки инициируются собственниками, внешними к данной отрасли, однако обладающими долями участия в нескольких конкурирующих фирмах. Частичные поглощения, в отличие от полных слияний и поглощений, не ограничивают необратимо и полностью конкуренцию между компаниями. Однако компании после осуществления такой сделки будут иметь возможность и стимулы в одностороннем порядке ухудшить конкурентное состояние в результате потери соперничества между ними. Так как для антимонопольных органов частичные поглощения могут представлять определенный интерес. Следовательно, растет актуальность оценок создаваемых ими односторонних конкурентных эффектов. В настоящее время в России не проводится детальная оценка вероятности наступления односторонних эффектов от сделок разных типов на рынке слияний и поглощений, но она потенциально возможна в российской антимонопольной практике.

Расчет агрегированного индекса валового повышения ценового давления (далее GGUPPI), используемый для оценки односторонних эффектов как от полных, так и от частичных слияний и поглощений, относится к группе методов симулирования слияний. Можно сделать вывод о возможности применения вышеназванного показателя в России в комбинации с уже используемыми методами экономического анализа с целью создания более широкой доказательной основы для принятия решений российскими антимонопольными органами. Это имеет существенное значение для разработки практических рекомендаций в области совершенствования государственного регулирования рынка слияний и поглощений.

Так как GGUPPI может быть вычислен с использованием данных, предоставляемых компаниями в соответствии с требованиями обязательного раскрытия информации, следует сделать вывод о возможности его расчета не только специалистами антимонопольных органов, но также инициаторами предполагаемых сделок, сторонними независимыми оценщиками и экспертами, что будет способствовать снижению неопределенности и пресечению асимметричности информации на российском рынке слияний и поглощений.

При аккумулировании данных расчетов GGUPPI для разных типов слияний и поглощений становится возможным создание информационных таблиц, где в зависимости от отрасли, типа предполагаемой сделки, долей первичного и итогового распределения финансового участия и корпоративного контроля будут представлены данные о вероятности наступления односторонних эффектов от сделки. В перспективе это поможет значительно упростить процедуру предварительной оценки предполагаемой сделки и сделает ее более прозрачной, что также снизит трансакционные издержки данной процедуры.

\section{Заключение}

Подводя итоги, в связи с наличием вышеобозначенных дисфункций российского рынка слияний и поглощений предлагается 
внести рекомендации о совершенствовании оценочного аппарата в антимонопольной практике в принятую ФАС России «Стратегию развития конкуренции и антимонопольного регулирования в Российской Федерации на период 2013-2024 гг.» и разработанные ФАС России «Разъяснения по порядку и методике оценки соглашений о совместной деятельности». Такие меры будут полезны в рамках развития формирующегося в России института разъяснений («guidelines») с целью устранения асимметрии информации между органами антимонопольного регулирования и хозяйствующими субъектами, а также для обеспечения единообразия правоприменения в сфере антимонопольного регулирования. Для инициаторов предполагаемых сделок слияний и поглощений это будет возможностью сформировать устойчивые ожидания относительно вердикта антимонопольных органов касательно решения о разрешении сделки и соответствующем моделировании дальнейших действий. Для работников ФАС России, членов общественных и экспертных советов при ФАС России это снизит вероятность осуществления ошибок при предварительной оценке предполагаемых сделок слияний и поглощений.

Таким образом, совершенствование оценочного аппарата экономического анализа в антимонопольной практике, расширение неформального контроля (проведение независимых экспертных исследований предполагаемых значимых сделок, а также анализа свершившихся сделок) будут способствовать ликвидации «двойных стандартов» в правоприменении антимонопольных норм и снижению вероятности осуществления ошибок при предварительной оценке антимонопольными органами предполагаемых сделок, что в целом повысит адаптивную эффективность существующих формальных норм, регулирующих взаимодействия на российском рынке слияний и поглощений. Это потенциально блокирует институциональную ловушку в сфере применения оценочных норм, снижает трансакционные издержки и сдерживает стимулы субъектов российского рынка слияний и поглощений реализовывать сложившиеся за последние 25 лет негативные неформальные практики взаимодействий.

\section{СПИСОК ЛИТЕРАТУРЫ}

Антоненко, Н. С. Основные тенденции развития российского крупного бизнеса в 2000-е годы / Н. С. Антоненко, Я. С. Галухина, Я. Ш. Паппэ // Журнал новой экономической ассоциации. - 2013. - № 1. - С. 114-136.

Балацкий, Е. В. Проблемы оценки масштабов и эффективности государственного участия в экономике / Е. В. Балацкий // Вестник Московского университета. Серия 6, Экономика. 1997. - № 6. - С. 22-44.

Барсукова, С. Ю. Новый российский капитализм: институционализация коррупции / С. Ю. Барсукова // Россия и современный мир. - 2016. № 4. - C. 21-39.

Зельднер, А. Г. Системные дисфункции государственного управления: институциональный подход / А. Г. Зельднер, В. С. Осипов // Экономика и предпринимательство. - 2015. - № 8-2. C. $127-131$.

Лякин, А. Н. Участие государственных корпораций в процессах слияний и поглощений / А. Н. Лякин // Вестник Санкт-Петербургского университета. Серия 5, Экономика. - 2010. - № 4. С. 43-55.

Радыгин, А. Д. Рынок слияний и поглощений: новые теоретические подходы / А. Д. Радыгин, Р. М. Энтов // Экономическая политика. 2010. - № 5. - С. 67-91.

Розанова, Н. М. Политика поддержки конкуренции в России: вчера, сегодня, завтра / Н. М. Розанова // Journal of Economic Regulation. - 2015. № 3. - C. 6-21.

Сухарев, О. С. Экономическая теория институциональных изменений: подходы к моделированию коррекции и дисфункции институтов / О. С. Сухарев // Журнал экономической теории. - 2018. - № 2. - С. 276-290.

Шаститко, А. Е. Широкие перспективы и овраги конкурентной политики / А. Е. Шаститко, Н. С. Павлова // Экономическая политика. 2018. - № 5. - C. 110-133.

\section{REFERENCES}

Antonenko N.S., Galukhina, Ya.S., Pappe Ya.Sh. Osnovnye tendentsii razvitiya rossiyskogo krupnogo biznesa v 2000-e gody [The Main Trends in the Development of Russian Big Business in the 2000s]. Zhurnal novoy ekonomicheskoy assotsiatsii [Journal of the New Economic Association], 2013, no. 1, pp. 114-136.

Balatskiy E.V. Problemy otsenki masshtabov i effektivnosti gosudarstvennogo uchastiya $\mathrm{v}$ 
ekonomike [Problems of Assessing the Scale and Effectiveness of State Participation in the Economy]. Vestnik Moskovskogo universiteta. Seriya 6, Ekonomika [Moscow University Economics Bulletin], 1997, no. 6, pp. 22-44.

Barsukova S.Yu. Novyy rossiyskiy kapitalizm: institutsionalizatsiya korruptsii [New Russian Capitalism: Institutionalization of Corruption]. Rossiya $i$ sovremennyy mir [Russia and the Conteporary World], 2016, no. 4, pp. 21-39.

Zeldner A.G., Osipov V.S. Sistemnye disfunktsii gosudarstvennogo upravleniya: institutsionalnyy podkhod [Systemic Dysfunctions of Public Administration: Institutional Approach]. Ekonomika i predprinimatelstvo [Journal of Economy and Entrepreneurship], 2015, no. 8-2, pp. 127-131.

Lyakin A.N. Uchastie gosudarstvennykh korporatsiy v protsessakh sliyaniy i pogloshcheniy [Participation of State Corporations in Mergers and Acquisitions]. Vestnik Sankt-Peterburgskogo universiteta. Seriya 5, Ekonomika [St Petersburg University Journal of Economic Studies], 2010, no. 4, pp. 43-55.
Radygin A.D. Rynok sliyaniy i pogloshcheniy: novye teoreticheskie podkhody [Market of Mergers and Acquisitions: New Theoretical Approaches]. Ekonomicheskaya politika [Economic Policy], 2010, no. 5, pp. 67-91.

Rozanova N.M. Politika podderzhki konkurentsii v Rossii: vchera, segodnya, zavtra [Competition Policy in Russia: Yesterday, Today, Tomorrow]. Journal of Economic Regulation, 2015, no. 3, pp. 6-21.

Sukharev O.S. Ekonomicheskaya teoriya institutsionalnykh izmeneniy: podkhody $\mathrm{k}$ modelirovaniyu korrektsii i disfunktsii institutov [Economic Theory of Institutional Change: Approaches to Modeling the Correction and Dysfunction of Institutions]. Zhurnal ekonomicheskoy teorii [Russian Journal of Economic Theory], 2018, no. 2, pp. 276-290.

Shastitko A.E., Pavlova N.S. Shirokie perspektivy i ovragi konkurentnoy politiki [Broad Prospects and Ravines of Competition Policy]. Ekonomicheskaya politika [Economic Policy], 2018, no. 5, pp. 110-133.

\section{Information about the Author}

Anastasia G. Alekseenko, Postgraduate Student, Assistant Lecturer, Economic Theory and Investment Department, Kuban State Technological University, Moskovskaya St., 2, 350042 Krasnodar, Russian Federation, harbourage@yandex.ru, https://orcid.org/0000-0002-9912-2563

\section{Информация об авторе}

Анастасия Германовна Алексеенко, аспирант, ассистент кафедры экономической теории и инвестиций, Кубанский государственный технологический университет, ул. Московская, 2, 350042 г. Краснодар, Российская Федерация, harbourage@yandex.ru, https://orcid.org/0000-0002-9912-2563 